OPEN ACCESS

Edited by:

Mei Wang,

WHU - Otto Beisheim School of Management, Germany

Reviewed by:

Lea Shih,

University of Trier, Germany

Toan Luu Duc Huynh,

University of Economics Ho Chi Minh

City, Vietnam

*Correspondence:

Paul Kadetz

paulkadetz@gmail.com

Specialty section:

This article was submitted to

Migration and Society,

a section of the journal

Frontiers in Human Dynamics

Received: 13 September 2021

Accepted: 13 December 2021

Published: 03 February 2022

Citation:

Kadetz P and Stanley-Baker M (2022)

About Face: How the People's

Republic of China Harnessed Health to

Leverage Soft Power on the

World Stage.

Front. Hum. Dyn 3:774765.

doi: 10.3389/fhumd.2021.774765

\section{About Face: How the People's Republic of China Harnessed Health to Leverage Soft Power on the World Stage}

\author{
Paul Kadetz ${ }^{1,2 *}$ and Michael Stanley-Baker ${ }^{3,4}$ \\ ${ }^{1}$ Institute for Global Health and Development, Queen Margaret University, Musselburgh, United Kingdom, ${ }^{2}$ Shiley-Marcos School \\ of Engineering, University of San Diego, San Diego, CA, United States, ${ }^{3}$ History, Nanyang Technological University, Singapore, \\ ${ }^{4}$ Lee Kong Chian School of Medicine, Nanyang Technological University, Singapore
}

In the fifteen year period from 1964-1979, The People's Republic of China engaged in an unprecedented number of domestic and international health campaigns that were utilized for China's entrance onto the world stage. From Mao Zedong's vision of a new form of medicine via the unification of Chinese medicines and biomedicine to the adoption of a Chinese model of healthcare integration and primary healthcare by the World Health Organization in the Declaration of Alma Ata, the PRC entered the world stage through its health exports and its distinctive adaptation of modernity to serve domestic, and often foreign policy goals. These exports include Sino-African health diplomacy; the globalization of Traditional Chinese Medicine, and in particular the global utilization and scientific recognition of the antimalarial artemisinin derived from the Chinese herb Qinghao; and a model of primary and rural universal healthcare utilizing community health workers that garnered multilateral support. However, the face of benevolence displayed on the world stage was often contradicted by what was occurring domestically, behind the scenes, with the marked state enforcement of many of these same health campaigns in front of the backdrop of the cultural revolution. This paper examines if, and how, the West may have orientalized and romanticized China's healthcare exports. Furthermore, we analyze the World Health Organization's adoption and global promotion of a model for universal healthcare using healthcare integration that was only able to be achieved through the often brutal enforcement of the state, whilst rejecting grass-roots movements enacted during the same period, such as the practitioner-led integration of Ayurvedic medicine in India.

Keywords: China, soft power, health, Mao Zedong, the World Health Organization, health diplomacy, Chinese cultural migration

\section{INTRODUCTION}

In the 15 year period from 1964-1979, The People's Republic of China (PRC) engaged in an unprecedented number of domestic and international health activities that, at least in part, supported China's entrance onto the world stage. From Mao Zedong's vision of a new form of medicine via the unification of Chinese medicines and biomedicine, to the adoption of a Chinese model of healthcare integration and primary healthcare by the World Health Organization (WHO) as part of the Declaration of Alma Ata, the PRC engaged the world through its health exports and its distinctive 
adaptation of modernity to serve foreign policy goals. These health exports include Sino-African health diplomacy; the globalisation of acupuncture and traditional Chinese medicines; and the global export of a model of primary and rural universal healthcare utilising community health workers (ie; 'barefoot doctors'). However, the face of benevolence that the PRC was displaying on the world stage often contradicted what was occurring domestically behind the scenes -with the marked state enforcement of many of these same health polices. This paper will examine how China used health as a form of soft power for its entry on the world stage.

\section{METHODS}

This paper is a culmination of several separate qualitative research studies concerning China's historical healthcare integration, The World Health Organization's adoption of a Chinese Model of primary and rural healthcare, and historical Sino-African health diplomacy. Archival research, semistructured, targeted stakeholder interviews, and participant observation were conducted at state, local, and multilateral levels of analysis, particularly for research concerning SinoAfrican Health diplomacy. Participant observation was also employed in the Western Pacific Region Office of the World Health Organization. Data was analysed employing content analysis. All research presented underwent institutional ethical review, and strictly followed methods to protect the autonomy and confidentiality of all informants.

\section{Theoretical Frameworks: Soft Power, Gifts, and Health}

In their 1917 report, the Rockefeller Foundation proposed 'Dispensaries and physicians have of late been peacefully penetrating areas of the Philippine Islands and demonstrating the fact that, for purposes of placating primitive and suspicious peoples, medicine has some advantages over machine guns' (Rockefeller Foundation, 1917: 42). The Rockefeller Foundation was actually making a case for the use of soft power in diplomacy. According to Nye, 'power means an ability to change the behaviour of states; to get others to do what they otherwise would not' (1990: 154). Soft Power refers to power that does not require political coercion or military intervention. Thus, 'soft power is the ability to obtain preferred outcomes in international relations by attraction rather than coercion or payment' (Nye, 2017).

But how does one state 'attract' another? Historically, international relations have been supported by gift giving. The sociologist Marcel Mauss' deconstruction of the social act of gift giving, in his classic monograph 'The Gift,' can help unpack the complex motivations embedded in foreign aid. For Mauss, gifts are symbolic keys that open doors to political and economic relationships. He defines the gift as 'the present generously given even when, in the gesture accompanying the transaction, there is only a polite fiction, formalism, and social deceit, when really there is obligation and economic self-interest' (Mauss, 1990: 43).
The Gift, therefore, establishes the crossing of a threshold, marking a symbolic entry into a relationship which is usually founded on non-equivalence and indebtedness, bound through webs of obligation (Adloff and Mau, 2006: 97). Mauss' conceptualization of gift giving is not restricted to western cultures. For example, consider how the Chinese concept of guanxi (关系) functions as an integral part of social, political, and economic relations, and how, like gift giving, guanxi creates bonds of mutual obligation and reciprocity that may build one's social capital, whilst perpetuating inequalities of power. Historically, the (specific) practice of gifting medicine for political ends in China dates back to at least the Tang dynasty, when the imperial house made a practice of giving gifts of expensive and exotic foreign medicines to imperial officials as reward for their allegiance and support. (Fan, 2007).

Mauss' conceptualisation of gift giving will be applied to this paper to better understand how health -which, as suggested by the Rockefeller Foundation, may be considered the ultimate and indisputable gift of beneficence; a kind of trojan horse in which political and economic agendas may be conveniently hidden and transmitted among populations- was leveraged by China in order to become a major player on the world stage.

In this paper, we will examine four major health related activities that supported China's soft power on the world stage: 1) Mao Zedong's integration of Chinese medicines and biomedicine to redress inequitable rural healthcare access; 2) how this integration facilitated the global exportation of so-called Traditional Chinese Medicine that was further promulgated by the WHO's adoption of the Chinese medicinal herb, Herba Artemesia Annua (Qing Hao, 青蒿) to treat Malaria, and $\mathrm{Tu}$ You You's subsequent Nobel Prize for her discovery of this application; 3) China's health diplomacy, particularly to African contexts; and 4) China's reentry into the United Nations, and the adoption of China's integrated healthcare model as a means to achieve universal healthcare by the WHO.

\section{THE GIFT OF INTEGRATION: IT ALL BEGINS WITH MAO ... OR DOES IT}

Anthropologist, Mary Douglas, refers to the inherent drive of social groups to make order and meaning out of chaos, as 'a unity of experience' (1966: 3). The literature on healthcare integration (defined here as the adoption of non-biomedical practices and/or practitioners into the biomedical healthcare system) reflects this idea of a unity of situated rationalities through terms such as 'unification' [Mao Zedong]; 'harmonisation' [ASEAN]; and, of course, 'integration' [WHO] (Kadetz, 2012). Thus, the representation of a top-down coherence of order, as opposed to a dynamic, fluid, and grass-roots multi-plural order, is normatively depicted as necessary and beneficent for effective healthcare.

\section{Ring Out the Old}

The story of healthcare integration in the PRC is an outcome of the intense pressures China experienced from the nineteenth to 
twentieth centuries to bridge the divide: between the old China and modern China; between the superstitious and the 'scientific'; and between the authoritative knowledge of the west and local (geographic, political, and historical) understandings. The impact of these pressures on local healthcare practices and practitioners in China reached an impasse in the early Republican period.

At the heart of the Westernisation Movement (yangwu yundong 洋務運動) (c. 1860s-1890s), was the adoption of western knowledge and technology (Ma, 1995: 25). Andrews (2014) suggests that the modernization of the various schools of Chinese medicine, in particular, was an outcome of these pressures to modernize. 'Chinese physicians mobilized western knowledge as a resource to defend themselves and the values they aimed to uphold' (Andrews, 1996: 2). Although a distinct shift in the Imperial Court's attitude toward modernity and biomedicine can be identified from the time of the Self Strengthening Movement (Ziqiang yundong 自强运动), c.1861 to 1895, it was not until after the Revolution of 1911 with the collapse of the Qing Dynasty, along with the Manchurian Pneumonic Plague (1910-1911) and the subsequent International Plague Conference (hosted by China), that the government truly embraced biomedicine ${ }^{1}$ (Wu, 1959; Andrews, 2014). A new metropolitan, biomedical elite was quickly established who worked in cities and catered to wealthy patients, and who 'were able to acquire some of the status and authority of the state' (Andrews, 1996: 15).

Under Chiang Kai-shek and the Nationalist government, health became equated with national strengthening, and the Ministry of Health of China was inaugurated in 1928; representing the first steps toward a health bureaucracy under the Nationalist regime (Yip, 1982). Having embraced western modernity, the Republican government set out to eradicate the various practices of Chinese medicine completely. Starting in 1914, the Ministry of Education proposed to abolish all Chinese medicine practices (Ma, 1995). ${ }^{2}$ This was followed by the 1929 bill entitled Abolishing the Old Medicine In Order To Clear the Obstacle for Health and Medicine that was adopted by the Ministry of Health ${ }^{3}$ (ibid.). The domination of Chinese health organizations by western-trained physicians 'with their generally unsympathetic attitude toward traditional doctors and their attempts to regulate or even abolish traditional medicine, led to a prolonged and often bitter feud between the two groups' (Yip, 1982: 1,201).

However, there was a small contingent of scholar-practitioners of Chinese medicine known as the School of Merging [Chinese

\footnotetext{
${ }^{1}$ At this conference, the Viceroy of Manchuria, Xi Liang, stated: 'We Chinese have believed in an ancient system of medical practice, which the experience of centuries has found to be serviceable for many ailments, but the lessons taught by this epidemic, which until practically 3 or 4 months ago had been unknown in China, have been great, and have compelled several of us to revise our former ideas of this valuable branch of knowledge' (Wu, 1959: 48).

${ }^{2}$ The Ministry of Education announced 'This Department has decided that all medical schools must provide courses of anatomy, chemistry and other sciences. Without these, one cannot study medicine' (Ma, 1995: 215).

${ }^{3}$ According to this proposed law, all publications about Chinese medicines would be barred, and any schools of Chinese medicine would be closed (Ma, 1995).
}

and western medicine] (huitong pai 匯通排), who, from the late nineteenth century to the end of the Republican era, sought to preserve Chinese medicine by hybridizing it with biomedicine (Scheid, 2001: 370). They promoted Chinese medicine as 'essential to Chinese culture' and were part of a larger national movement, which opposed the wholesale adoption of western culture (Andrews, 1996: 15). Yet, they also believed it detrimental to ignore biomedicine, and instead sought to validate the impacts of Chinese medicine via biomedicine (Ma, 1995). 'Their efforts ranged across a wide spectrum from assimilation of certain western ideas into Chinese medicine to the use of biomedical knowledge to instigate total reform of Chinese Medicine' (Scheid, 2001: 370-1). They attempted to standardize the teaching and practice of Chinese medicine through government licensing of schools and practitioners (ibid.). Yet, they simultaneously dismissed many Chinese 'popular medical practices as ignorant superstition unworthy of scholarly consideration' (Andrews, 1996: 16).

The School of Merging called for a huitong (會同), or synthesis of Chinese medicine and biomedicine. Several of these 'reformers' opened their own schools (Ma, 1995). 'The first of these, Liji Medical School, opened in 1885 and offered elementary western medical education courses such as anatomy, psychology, and public health' (ibid: 221). The school also offered a teaching hospital and a medical journal (ibid.). Although several of these modernised Chinese medicine schools opened during this period, none were documented to have survived the 1911 Revolution (ibid.). Nevertheless, these early attempts at a grass-roots integration of Chinese medicine with biomedicine introduced the possibility of 'modernizing' the practices of Chinese medicine, as well as suggested the potential future for healthcare integration into the consciousness of several influential reformers; reformers who were later to be subsumed into Mao's integration 'from above'.

\section{Mao's Integration: The Enforced Redressing of Rural Healthcare Inequities in China}

Lucas (1982: 1) maintained that the various political upheavals stemming from the 1949 revolution to the Cultural Revolution did not ultimately alter the basic policies of national medicine that were diffused across China in the late 1920s. 'There was little dispute in China that the Ministry of Health, established after the foundation of the People's Republic of China in 1949, was to function entirely on the basis of biomedicine' (Taylor, 2005: 6). Mao's original platform for the Chinese Communist Party (CCP) was solely focused on modernizing China. During the formation of the CCP, Mao Zedong wrote his key text, 'On New Democracy' (Xin min zhu zhu yi lun 新民主主義論), published in 1940, in which he emphasized: 'We want not only to change a politically oppressed and economically exploited China, but also to change a China which has been ignorant and backward under the rule of the old culture into a China that will be enlightened and progressive' (quoted in Taylor, 2001: 344). Four years later, Mao stressed: 'This type of new democratic culture is scientific. It is opposed to all feudal and superstitious ideas; it 
stands for objective truth and for unity between theory and practice' (ibid: 345). In fact, Mao singled out Chinese medicine as a 'hindering factor toward the 'new democratic culture,' which required 'remolding' to become part of the revolutionary movement' (ibid.).

There are numerous conflicting reports concerning what Mao thought or said about Chinese medicine depending on when he said it and to whom. Regardless of Mao's rhetoric, modernizing healthcare in China presented a challenge for the CCP. Of the between 21,000 and 40,000 biomedical physicians practising in China in 1949, the vast majority catered to metropolitan elites; refusing to work in the poor rural areas dominating the Chinese landscape (Sidel, 1973: 20). This twotiered system resulted in a markedly increased inequity of rural healthcare that challenged the goals of the CCP and resulted in an immediate issue for the new government to address (ibid.). Mao began to address this disparity in his 1940 essay, On New Democracy. Interestingly, after disparaging Chinese Medicines in On New Democracy, Mao also states: 'If we only rely on the new medicine [biomedicine], we will not be able to solve our problems. Of course the new medicine is superior to the old medicine, but if they [the doctors of the new medicine] are not concerned about the sufferings of the people, do not train doctors to serve the people, and do not unite with the thousand old doctors of the old school in order to help them improve, then they will actually be helping the practitioners of witchcraft by callously observing the death of a large number of men. Our task is to unite with the old style doctors who can be used, and to help educate and remould them. In order to remould them we must first unite [with them]' (quoted in Taylor, 2001: 346).

Hence, Mao's criteria for the development of a 'New Democracy' demanded that practices, including healthcare practices, must be new (xin 新), scientific (keuxue 科學), and unified (tuanjie 團結) (Taylor, 2001: 344). Thereby, the 'old style doctors' (Jiu yisheng 舊醫生) were to be modernized and united with the 'doctors of the new medicine' (Xin yi 新醫), in order to improve human resources that will serve to remedy inequitable rural healthcare access; which was not being addressed by depending on the urban, elite biomedical physicians. Furthermore, barefoot doctors (chijiao yisheng, 赤脚医生), community health workers, who were chosen by their communes to receive basic training in both biomedicine and Chinese medicine, represented the embodiment of this integration at the most local level of rural healthcare. On New Democracy foreshadows many of Mao's future concerns and actions for rural healthcare.

What ultimately motivated Mao to promote the Chinese medicine he formerly disparaged is debatable. However, Mao's shift needs to be understood within the particular political context of the breakdown of Sino-Soviet relations; a political event which caused Mao to adopt a kind of 'practical nationalism' that served to justify survival by means of China's own resources. This nationalism is reflected in Mao's statement that 'Chinese medicine is a great treasure house'; inferring that Chinese cultural genius of the past can be mined for contemporary science and, potentially, for global distribution. Similarly, we can question if this repackaging and 'scientisation' of the practices of Chinese medicine to suit communist tastes might not also have been employed to visibly demonstrate the fruits of Chinese communism.

Mao's situation in the 1950s was similar to the quandary that Fidel Castro later faced in the 1990s, when, what is now known as Medicina Traditional y Naturale (ie; Traditional and Natural Medicine), was developed in order to fulfil the promise of the Cuban communist constitution for universal healthcare; following the severe reduction of healthcare resources with the dissolution of Cuba's main trading partner, the USSR, and the concomitant increased severity of the US embargo to Cuba (Kadetz and Perdomo, 2011). Thus, might integration of Chinese medicine with biomedicine ultimately have served as a means to save the CCP from losing face, particularly given the, then, rural majority of the PRC?

\section{Speaking of Integration}

Throughout the 1940s, Mao continued to stress the political slogan that 'Chinese and western medicine should join together' (zhongxiyi tuanjie 中西醫團結) (Taylor, 2001: 361). But the integration of Chinese medicine and biomedicine was only meant to be a first step toward Mao's final goal of unification (Taylor, 2005). Mao sought to alter Chinese medicine via biomedicine in order to yield a new unified medicine that was neither traditional medicine nor biomedicine, but a modern Chinese hybrid meant to be greater than the sum of its parts (ibid.). ${ }^{4}$

However, Mao was met with tremendous resistance from practitioners, as well as from the CCP, and ultimately was only able to achieve the first step of unification, (i.e. integration) (Taylor, 2005). From the mid-1950s, Mao specifically called for integration of biomedicine and Chinese medicine with the slogan 'Chinese and Western medicine should be integrated' (zhongxiyi jiehe 中西醫結 合) (Taylor, 2001: 361). Similar to the aims of the School of Merging, the process of what Mao called integration was meant to 'raise Chinese medicine to a higher' scientific level, comparable to biomedicine (Taylor, 2005). Thus, integration in China was to be the standardization of, what were at the time, the many different schools of Chinese medicine practice along a biomedical framework (Unschuld, 1985).

To achieve integration, Mao employed biomedical physicians, primarily from the Ministry of Health, as well as from biomedical schools, such as the Rockefeller-funded Peking Union Medical College (PUMC), to comb through the practices of Chinese medicine and remove any superstitious or spiritual elements, whilst maintaining those elements that were more aligned with biomedicine and capable of being standardised (Taylor, 2005). ${ }^{5}$

${ }^{4}$ It is interesting to note, that though the WHO acknowledges their adoption of Mao's model of integration, any mention of his intended goal of unification toward a new hybrid medical system, cannot be located in the WHO literature reviewed [not available in Crossref].

${ }^{5}$ According to Zhu Lian, an early proponent of integration in the CCP; 'Reform does not mean that Chinese medicine should drop all its original theories [...] instead we need to choose those areas of ancient medicine which are appropriate, drop those areas which are not appropriate, use scientific methods, sort out the experience [...] so as to improve its scientific theory' (quoted in Taylor, 2001: 360) 
In this manner, what was to become the normative representation of healthcare integration was, in actuality, a hybridization process of both Chinese deculturation and Eurocentric biomedical acculturation. What was developed by these biomedical physicians is what is now generically referred to (in English) as traditional Chinese medicine or TCM, commonly referred to in Chinese as zhongyi (中医) ${ }^{6}$ or 'Chinese medicine', as opposed to simply 'medicine' or $y i$ (医). Eventually, TCM was incorporated into hospitals and clinics throughout China and employed for any given patient in combination with biomedicine (Hsu, 2018).

The confusion often surrounding China's representation of healthcare integration is that the practice of using TCM in hospitals or clinics in conjunction with biomedicine is what is being identified as integration. However, what is portrayed as integrated, in this instance, is itself an already integrated system of various schools of Chinese medicine practices that were standardize by biomedical physicians. Although TCM may be differentiated from the varied practices of its precursors, even the different schools of Chinese medicine are arguably more standardized than most local healing practices worldwide. Hence, it is important to acknowledge that, in actuality, few local health practices in the world are as standardized, or even capable of being as standardized, as integrated TCM or its many precursors.

\section{EXPORTING [THE GIFTS OF] CHINESE CULTURE: THE GLOBALIZATION AND RECOGNITION OF TRADITIONAL CHINESE MEDICINE}

The integration of the myriad schools of Chinese medicine into a single standardised form, served to facilitate its dissemination as a global export, thereby, realising Mao's proclamation of Chinese Medicine's status of 'national treasure'. 'The total value of TCM import and export in 2016 was 4.6 billion USD, accounting for $4.45 \%$ of the total value of the import and export of Chinese pharmaceutical products' (Lin et al., 2018:1). Chinese medical practices were exported through several venues.

Historically, trade has offered a fundamental platform for cultural exchanges, including medical practices. For example, China has a long history of trade with the African continent, dating to the 1 st century CE. 'Africa attracted China as early as the T'ang dynasty (A.D. 618-907)'; and during the Song dynasty (A.D. 1127-1279), 'Chinese shipping was common throughout the western reaches of the Indian Ocean (Rotberg, 2009: vii). A Chinese cartographer, Zhu Siben朱思本 (1273-1337),

${ }^{6}$ Formally, TCM has been referred to as chuantong zhongyi (傳統中醫) by Ma Kanwen during the 1970s. However, prior to the introduction of biomedicine from western missionaries, there was no need to differentiate Chinese medicines from the biomedicine of the west, and medicine in China was simply called Yiyao (醫藥) or medicine. During the Republican Era and the construction of the modern Chinese state, Chinese medicine was known as Guoyi (國醫), or 'state-sanctioned medicine'; simultaneously associating cultural nationalism with statism (Lei, 2014: 110) assembled one of the first maps of the Southern region of the African continent in 1320, which actually predates any western map by 150 years (Harley, 1994). During the Han Dynasty (208 BCE to $220 \mathrm{CE}$ ), the development of the Silk Road provided a means for trade between China and Africa (Sun and Lancaster, 2013). The first cultural exchanges between China and Africa undoubtedly resulted from these exchanges of trade.

Similar to the impact of the movement of cultural outputs via trade, is the movement of people via migration. From the mid19th century, with the so-called 'coolie migration', an estimated 40 to 45 million Chinese migrated from China to more than 180 countries (Tan, 2013). However, global migration of Chinese was in effect well before the 19th century. For example, some of the first Chinese to arrive in colonial Africa in the 17th century, particularly to the Dutch-occupied Cape, were convicts or exconvicts, banished to the Cape from Batavia in the former Dutch East Indies (Armstrong, 1997). The convicts who chose to remain in Africa after the completion of their jail terms were classified as 'free blacks' (Yap and Man, 1996: 6). Similar to the diaspora of Chinese migrants to other contexts, 19th century labour migrants were contracted through colonial empires. 'After the Opium Wars of the 1840 s and 1850 s, China was forced by the colonial powers to reduce restrictions on Chinese emigration, which saw the beginning of large-scale movements of Chinese overseas in the form of the coolie trade' (Mohan and TanMullins, 2009: 592; Yap and Man, 1996). The migrants came to Africa believing in the prospect of a better financial future, even though, in reality, hardship and sometimes indentured servitude awaited poor Chinese migrants.

Although both the Chinese Diaspora and international trade may have introduced Chinese herbal medicines, acupuncture, and other medical practices into myriad ports of arrival, Chinese medical practices were not mainstream, particularly in the West. However, in 1971, the U.S. National Security Advisor, Henry Kissinger, made a secret visit to China to lay the groundwork for then, President Nixon's visit to China in 1972. Kissinger was accompanied by a New York Times reporter, James Reston, who required an emergency appendectomy while in China, and was treated with acupuncture for post-surgical pain. Reston's front page New York Times' reports of his experience with acupuncture was one of the first of such testimonials to reach the mainstream western media (Li, 2014).

Myriad similar factors resulted in the extensive penetration and utilization of Chinese medical practices throughout the world. As of 2007, in the U.S. alone, there were about 40,000 acupuncturists who practice under a national board certification system; nearly a hundred schools of acupuncture; and 10-15\% of federal funding for complementary and alternative medicine that was allocated for acupuncture research (Li, 2014). Approximately 6.8\% of American adults have used acupuncture, with a total treatment number of 17 , 600,000 annually, and spending \$823 Million USD out of pocket for acupuncture (ibid.). Furthermore, the Chinese government continues to develop and expand their reach in the marketplace. According to Guanne (2021), The One Belt, One Road Development Plan for Chinese Medicine (2016-2020), already reached its target of building 30 overseas centres of Chinese medicine in 2018. 
Other factors that have supported the global dissemination of Chinese medicines include the acceptance of foreign students into China to study TCM, beginning in the 1970s; the western youth counterculture movements and their embrace of Orientalism in the 1960s; and, most notably, the global success of the Chinese herb, Qinghao (青蒿, Herba Artemesia Annua) in treating malaria.

$\mathrm{Tu}$ Youyou (awarded the Nobel Prize in 2005 for her discovery that artemisinin, an extract from Qinghao, was effective at inhibiting the malaria parasite) was actually one of the biomedical professionals trained in Chinese medicines (from 1959-1962) under Mao's efforts to integrate biomedicine and Chinese medicines (Nobelprize.org, 2021). Drug-resistance of the malaria causing plasmodium falciparum to quinoline therapies resulted in the need for alternatives. In reviewing the ancient Chinese herbal medicine literature for the treatment of malaria, Youyou tested Qinghao among the numerous herbs identified (ibid.). A drug effective in the treatment of malaria was produced from an active ingredient of Qinghao, artemisinin (ibid.).

In myriad ways, Youyou's work fulfilled Mao's portrayal of Chinese medicines as a national treasure to be exported and recognised worldwide, and was highlighted in her depiction of Chinese medicines as a gift in her Nobel Prize acceptance speech entitled: 'Discovery of artemisinin - A Gift from Traditional Chinese Medicine to the World' (ibid.). However, it was the World Health Organization who effectively propelled the drug from bench to bedside with their 2001 endorsement of Artemisinin-based combination therapies (ACTs) for first-and second-line treatment for uncomplicated P. falciparum malaria, and well as for chloroquine-resistant P. vivax malaria (World Health Organization, 2018: 1). As we will see, this was not the first time the World Health Organization markedly enhanced the PRC's status on the global stage because of their work in healthcare.

All of these activities resulting in the global dissemination of Chinese medicines have effectively actualized Mao's projects to fulfil the promise of Chinese medicines as a national treasure; one that bridged the PRC's entry onto the world stage. However, another prominent means for the world-wide dissemination of Chinese medicines has been through China's health diplomacy.

\section{DO ONTO OTHERS: CHINA'S 'RE-ENGINEERED' GIFTS OF SOFT POWER}

For the purposes of this paper, we can think of health diplomacy as a form of soft power in which healthcare aid is used to improve political, economic, and/or cultural ties between donor and recipient countries in keeping with the foreign policy goals of the donor state. However, the practice of health diplomacy does not share a standardized, systematized, or universalized ideology. The numerous ideologies that have become embedded in China's foreign policy and health diplomacy can be understood as a function of the particular political agenda in Beijing at any given period. However, China's health diplomacy can be traced back to a particular ideological understanding of the function, structure, and role of aid in diplomatic relations, developed in the 1950s.
In April 1955, China and other 'developing' countries began to establish both political and economic ties to Africa at an international conference in Bandung, Indonesia. One of the primary outcomes of this conference was the development of a novel regional approach that was to become a normative ideology, characterizing South-South foreign policy and international cooperation, and that offered a marked alternative to the predominant American ideology of the 'Washington Consensus,' emanating from post-World War II reconstruction and the Truman Doctrine. Central to the ideology developed in Bandung are the so-called 'Five Principles of Peaceful Coexistence', first articulated by China, India, and Burma, which established the foundations of Chinese and Indian foreign policy, as well as Asian regional diplomacy in general; particularly within the Association of Southeast Asian Nations (ASEAN). Then, in 1964, Zhou Enlai announced that Beijing's policy toward sub-Saharan Africa would be based on both the Five Principles, as well as the 'Eight Principles of Economic Aid'. Most significant to both were the ideas that aid should not violate the recipient's sovereignty, and that aid should be offered without conditionalities, both of which have remained a cornerstone of China's foreign aid practices.

In addition to these policies, China has consistently represented itself as a unique and irrefutable alternative to western aid by being a natural ally of low-income countries in the fight against 'imperialism and hegemony' of the superpowers. But moreso, China portrayed itself as the leader of the so-called 'third world'. Unlike the Soviet Union, the Chinese government presented itself to African states as a patron that rejected the imperial mandates of Western powers (particularly those of the USA) and understood the unique struggles of peasant movements.

China has a long, often unacknowledged history of providing foreign aid to Africa, that was built upon mutually beneficial partnerships that emphasized the term 'cooperation'. China successfully characterized its relationships in Africa as equal, strategic partnerships of similarly-developing 'sister' countries in which mutually-beneficial cooperation replaced colonial paternalism. However, as discussed in Mauss' conceptualization of The Gift, 'assistance programs do not exist apart from the relationships among the participants' (Gergen and Gergen, 1971). And to categorize China's development/aid policies as entirely free of conditionalities, regardless of Beijing's rhetoric, is simply not accurate. For, in order to be considered for Chinese aid, states have been obliged to support the 'One China' policy, in which the Republic of China (Taiwan) is not to be recognized as a separate state from the PRC. Regardless of the presence of this ideological conditionality within a discourse of 'no strings', China has successfully presented itself as a natural ally of low-income countries, and has enhanced its credibility among African governments, achieved, at least in part, through Sino-African Aid. Overall, China's aid to other countries 'has been increasing by $25 \%$ annually, reaching US\$7 billion in 2013, with 52\% of all types of overseas aid concentrated in Africa, a majority of which has been invested in infrastructure, including buildings, factories, human resources, substantial loans, and health diplomacy (Tang et al., 2017: 2595). Although health diplomacy is but one element of China's engagement with Africa, it has played a predominant role. 
In $2014,45.7 \%$ of China's health aid was reported to be specifically targeted for Africa (Liu et al., 2014). Though considerably less than the contributions from many high income OECD-DAC countries, China's total health aid to Africa is estimated at $\$ 150$ million usd annually (Tang et al., 2017). Historically, China's health diplomacy may have been particularly successful in African contexts because of the actual health care interventions involved and because the structure of Chinese health diplomacy is significantly different from the normative health aid from Western donors. Professional human resources have always been a central component of Sino-African health diplomacy. Since the first medical team arrived in Algeria in 1963, more than 23,000 Chinese medical personnel have served in 47 different African states and treated at least 180 million patients (Liu et al., 2014; Tang et al., 2017; Youde, 2010). Historically, Chinese Medical Teams (CMTs) have been specifically targeted for rural, under-served communities with limited access to healthcare. CMTs are also noteworthy for including practitioners of traditional Chinese medicine (i.e., acupuncturists and herbalists), in addition to conventional biomedical personnel; which may have helped to further disseminate Chinese medical practices. For example, Chinese herbal remedies have been welcomed in many African contexts, where many local informal healthcare economies were already dominated by the use of herbals.

In addition to human resources, essential medicines, herbs, and acupuncture, China has also been integral in the development of healthcare infrastructure, both through the construction of hospitals and clinics throughout Africa and in the training of African medical students in China. According to informants interviewed, these healthcare provisions have both enhanced China's image in the eyes of ordinary Africans and engendered a trust in Chinese medical products (Kadetz, 2013). Brautigam's (2009) finding that 'China gives Africans more respect than they get from the West' was corroborated by several patient informants interviewed for this research. This may, in part, be an outcome of the fixed durations of many health interventions from the 'global north,' which often lack a follow-up from which sustainability can be assessed. According to Brautigam. (2009), 'For the West, once a project ends, it is turned over to the government, and donor involvement usually ends.' One outcome of this 'Western approach' is that even if projects have fulfilled the donors' specific short-term goals, many are unsustainable in the long term. However, China's projects are unsustainable specifically because CMTs will return to the same hospitals year after year, rendering local interventions unnecessary, whilst creating dependency on the CMTs.

Regardless of the actual long-term impacts of Sino-African health diplomacy, these gifts have had a marked soft power impact that may have, at least in part, been responsible for the PRC's re-entry into the United Nations in 1971. Although China was a member of the United Nations from its inception in $1948^{7}$,

${ }^{7}$ And, in fact, the Chinese delegate at the UN Conference on International Organization in 1945, Dr. T.V. Soong, was identified as 'the first person to suggest the founding of a single international health organisation' (Siddiqi, 1995: 110) the CCP's separation from the former Republican party of the Guomingtang in 1948, resulted in the division of China into the People's Republic of China and the Republic of China (Siddiqi, 1995). The UN agencies not knowing which 'China' to recognize as 'The China', eventually, with the support of the United States and other prominent Western nations, recognized the Republic of China as 'China' for diplomatic purposes (ibid). It was not until 1971, after the return of full membership to Soviet and other socialist states, in addition to the decolonisation of many African countries, that the decision of 1950 was reversed. The PRC's return to the United Nations was predominantly achieved through the vote of African states who supported a OneChina policy, purportedly as an outcome of China's aid and diplomacy with African States (Wang, 1996). Despite U.S. opposition, the PRC was now recognized as the UN member state of China and the Republic of China (ie., Taiwan) was expelled 'from the place they unlawfully occupied at the UN and in all organizations related to it' (American Society of International Law, 1972). This diplomatic shift had marked consequences in Chinese visibility and power, for as Nye (2004) identifies, participation in multilateral institutions, such as the United Nations, can provide a soft power platform for a country.

However, another significant health event that facilitated the PRC's entry onto the world stage was the adoption of China's primary healthcare model to achieve the WHO's goal of 'Health for All'; first by the World Health Assembly in 1976, and subsequently by the World Health Organization in the Declaration of Alma Ata in 1977.

\section{UNPACKING THE WORLD HEALTH ORGANIZATION'S ADOPTION OF AN ENFORCED MODEL OF HEALTHCARE}

In May 1977, the World Health Assembly of the World Health Organization announced its target of universal healthcare coverage for all by the year 2000; codified the following year in the Declaration of Alma Ata. Mao Zedong's utilisation of existing resources to achieve extensive rural healthcare coverage -including: the development of the primary level of rural healthcare; the training of community health workers; and the integration of local healthcare practices and practitioners into the biomedical healthcare system- was adopted by the WHO and embedded in the Declaration of Alma Ata as a means to achieve 'health for all'. However, 8 months previously, on September 9, 1976, Mao Zedong died, and with his death followed the rapid dissolution of rural healthcare coverage in the People's Republic of China. The Declaration of Alma Ata was adopted at the WHO's World Conference on Primary Healthcare in September 1978. Three months later, Mao's successor, Deng Xiaoping, instituted the first economic reforms of the PRC (Gaige kaifang, 改革开放) leading to the current economic system of state capitalism accompanied by an ongoing cycle of healthcare policies and reforms that have, to the present, sought to return rural healthcare coverage to its former capacities under Mao. 
The World Health Organization was formed as a technical agency of the United Nations in 1948 (Lee, 2009). Vertical disease treatment programming (which focuses on the eradication of a communicable disease, such as smallpox, or of a group of communicable diseases) was the dominant paradigm for WHO interventions, regardless of the more horizontal, social medicine, prevention, and healthcare resource building focus of its charter. Part of the reason for the preferential use of vertical programming at the WHO may be a consequence of the political economic dominance of a US agenda, that favoured vertical programming, following the departure of the Soviet Union, the PRC, and other communist countries shortly after the WHO began operations in 1949 (Brown, 1979). The Washington agenda sought 'modernization with limited social reform' (Brown et al., 2006: 65), which included the global market expansion of American pharmaceutical corporations and a concomitant emphasis on treatment, instead of prevention. Hence, the policy decisions and embedded frameworks of the WHO were, at least in part, a reflection of the agendas of larger international political economic alliances and hierarchies of power. Therefore, the WHO's marked shift in emphasis toward universal primary healthcare and preventative medicine via horizontal programming during the 1970s was novel and noteworthy.

Several factors are believed to have supported the adoption of what came to be known as Comprehensive Primary Healthcare (CPHC). These factors include:

1) a renewed appreciation in the 1960s of the need to strengthen healthcare infrastructure after assessing the failure of several vertical programs in low-income settings, such as malaria eradication programs;

2) the WHO's efforts to redress rural healthcare coverage which date to the 1960s;

3) the influence of the WHO's then director general, Halfden Mahler, and his prioritization for covering basic health needs;

4) the influence of the Soviet Union and their support for the horizontal promotion of national health services, which developed into primary healthcare services at the community level;

5) the readmission of the PRC as a member state of the World Health Assembly in 1973;

6) the support of several African nations (who had received aid from the PRC) for China's healthcare approach;

7) the world economic recession of the 1970s;

8) and the growing acknowledgment, especially in the west, of the PRC's success in rural health coverage (Litsios, 2004; Lee, 2009; Huang, 2010; Kadetz, 2013).

This last factor was particularly instrumental in inspiring the World Health Assembly to launch the 'Health for All by 2000' campaign. According to the former deputy director general of China's Department of Rural Health Management, in attempting to resolve the challenges identified in the 1970 s, related to the health-cost burden and unequal distribution of health resources, the WHO conducted research in nine countries, including four cooperation centres in the PRC (World Health Organisation, 2008). Also during this period, the normative biomedical healthcare model of disease eradication 'was failing to meet the basic needs of populations' in low-income countries and became an increasingly untenable model (Lee, 2009: 73). All of these factors, coupled with the marked gains of community-based models (particularly in Latin America and Bangladesh), which reflected significantly improved health outcomes despite resource-poor conditions (particularly in Cuba and Kerala), in addition to the purported success of the barefoot doctor program in the PRC, promulgated a paradigm shift in the WHO's approach to healthcare in low-income countries (ibid.).

This shift from a more vertical to a more horizontal approach, which supported an understanding of health as a human right, was endorsed by all 134 World Health Assembly member states attending the WHO conference at Alma Ata (Brown et al., 2006). The outcome of this conference (ie., the 1978 Declaration of Alma Ata), was a bold attempt by the WHO to achieve universal healthcare by prioritizing the development of primary healthcare resources. However, the WHO's vision for primary healthcare, which emphasized strong basic healthcare services at the most local community level, was challenged at a post-Alma Ata Rockefeller Foundation sponsored conference, for being too expensive, too broad, and too horizontal in implementation to be seriously considered for addressing universal healthcare (Magnussen et al., 2004). In its place, 'a rationally conceived, best data-based, selective attack on the most severe public-health problems' was proposed (Walsh and Warren, 1979: 970). In other words, the normative vertical curative approach that addresses the treatment of particular diseases, was (ironically) presented as 'the most effective means of improving the health of the greatest number of people' (ibid.).

This newly labelled approach of 'Selective Primary Healthcare' (SPHC), which was solely concerned with infant and child health, ${ }^{8}$ was touted as the best possible option for low-income countries 'until comprehensive primary healthcare can be made available to all' (Walsh and Warren, 1979: 970). This approach was supported by then World Bank president, Robert McNamara, and donor agencies including USAID, the Ford Foundation, and the Rockefeller Foundation (Brown et al., 2006). In other words, this decision was heavily orientated toward US policy and political economic considerations. The new Director of UNICEF, another American, James Grant, adopted SPHC as the framework through which UNICEF would immediately operate (ibid.). Thereafter, a partition was placed between the WHO's approach of Comprehensive Primary Healthcare and the Selective Primary Healthcare approach of UNICEF, and a debate was born in international health circles, which has continued for the past 4 decades.

Yet, Mao's model to redress rural healthcare access through community health workers and the integration of nonbiomedical practices and practitioners into the formal healthcare system was quietly and independently adopted by

\footnotetext{
${ }^{8}$ Selective Primary Healthcare at UNICEF was 'operationalized under the acronym "GOBI" (i.e.; Growth monitoring to fight malnutrition in children, Oral rehydration to fight diarrheal diseases, Breastfeeding and Immunizations)' (Brown et al., 2006: 67).
} 
several countries after Alma Ata. Hence, even though comprehensive primary healthcare was not ultimately globally adopted, Mao's model of primary healthcare -through integration of non-biomedical practices and practitioners into the biomedical healthcare system- shaped the discourse of healthcare integration, particularly in the WHO.

\section{DISCUSSION}

\section{Problematizing the Chinese Model Adopted by the World Health Organization}

The adoption of China's model for healthcare integration became an integral component of the Declaration of Alma Ata because of the favourable popular perception of China's success in redressing rural healthcare access via the integration of TCM and biomedicine, and possibly as an outcome of the soft power influence of Sino-African health diplomacy, as well as because of Chinese nationals in positions of power at the $\mathrm{WHO}$ at the time. However, as discussed, what the WHO has represented as healthcare integration, is not the integration of various local Chinese medical practices and biomedicine into the state healthcare system, but rather the integration of what was already an integrated system of TCM with biomedicine. The relevance of the WHO using TCM as a model for healthcare integration, whilst not acknowledging that TCM was itself an already integrated medical system, is that it: 1) falsely projects the idea that any non-biomedical practice can be successfully integrated into a national healthcare system, whilst disregarding the fact that few practices may be as systematized and standardized as TCM;2) may thereby be facilitating the integration of only those non-biomedical practices and practitioners that have been systematized, standardized, and legitimized by biomedicine; 3 ) makes it appear that integration can be achieved by any nation at any point in time, as comprehensively as the PRC appeared to do, regardless of political and socioeconomic contexts; and 4) reifies integration as only achievable as a top-down process. However, in actual practice, healthcare integration is neither a top-down process solely determined by the state, nor by its biomedical practitioners in positions of authority (Kadetz, 2014). Rather, healthcare integration may be best understood as an outcome of the medical pluralism dynamically practised by the lay public. However, in a context, such as Maoist China, where all healthcare practices and practitioners were controlled by the state, top-down integration may be the most accurate description of how integration was carried out in the context of the PRC.

Basing all healthcare integration on the integration of TCM and biomedicine in Maoist China can pose other important challenges when applied to other countries, or even to China today. Firstly, it is imperative to acknowledge that healthcare functions within a given political economy. The formation of TCM and the Barefoot Doctors program was conceived and implemented within an egalitarian-authoritarian socioeconomic system, which may not be easily transferable into other socioeconomic systems.

Secondly, although Mao believed that the integration of Chinese medicine could provide an opportunity to redress rural health inequities with the human resources that were readily available, he had to overcome marked opposition from biomedical physicians; Chinese medicine practitioners; ${ }^{9}$ the Ministry of Health ${ }^{10}$ and the early CCP, who originally sought to extinguish traditional medical practices (Lucas, 1982). ${ }^{11}$ Therefore, the rationale for the integration of the various schools of Chinese medicine into TCM could be understood more accurately as a compromise to rectify healthcare disparity within specific political and economic circumstances.

Since healthcare integration in China could not be achieved by complete consensus, coercion and force were employed (Rosenthal, 1981). This was accomplished on several fronts: 1) Mao took advantage of the nationalistic fervour that had erupted in China since the Treaty of Versailles (1919) and the May Fourth Uprising, which 'catalyzed the political awakening of a society which had long seemed inert and dormant ${ }^{12}$ (Meisner, 1999: 17); 2) Mao's rhetoric of Chinese medicine, as a 'national treasure' to serve alongside biomedicine, was more the product of a nationalist movement -that included a revival in many of the arts of China- than of any consideration of Chinese medicine's therapeutic value (Taylor, 2005); 3) Physicians were forced to engage in TCM studies. Those who resisted integration were labelled 'bourgeois', criticized, and/or exiled to distant areas (ibid.); 4) At the onset of the Cultural Revolution, the Ministry of Health was blamed for ignoring rural health. Speaking on the eve of the Cultural Revolution, Mao condemned the Ministry of Health: 'The Ministry of Health serves only $15 \%$ of the urban population. It should be renamed the Urban Health Ministry, or the Lords' Health Ministry [...] in medical and health work, put the stress on the rural areas!' (Sidel, 1973: 28). Eventually, the CCP took over complete administration of healthcare in order to facilitate integration; insisting that practitioners of Chinese medicine be placed in biomedical hospitals and clinics ( $\mathrm{Ha}^{\circ} \mathrm{klev}, 2005$; Rosenthal, 1981); and 5) During the Cultural Revolution, the same social pressures that had previously been directed towards biomedical physicians were now directed with even greater ferocity towards those Chinese medicine practitioners who

${ }^{9}$ For example, many Chinese medicine practitioners were called 'purists' for their rigidity in attempting to ensure the integrity of their system of Chinese medicine and they, like the Ministry of Health, emphasized the importance of maintaining boundaries to guarantee this integrity (Taylor, 2005).

${ }^{10}$ Despite CCP directives, the Ministry of Health, predominantly composed of graduates from medical colleges, such as the Rockefeller Foundation's PUMC, continued to oppose integration of Chinese and biomedicine throughout the 1950s (Farquhar, 1994; Lampton, 1974; Lampton, 1977). Mao attacked the Ministry for only being concerned with the urban elite, as well as for their sole focus on curative rather than preventative medicine; for over-dependence on the Soviet healthcare model; and for refusal to integrate TCM and biomedicine (Sidel, 1973; Lampton, 1974).

${ }^{11}$ Though according to Farquhar, the CCP has usually been credited with continual support for Chinese medicine in order to maintain 'a coherent historiography of the party' and its influence on medical history (1994: 13).

${ }^{12}$ The May Fourth uprising in 1919, was in reaction to the subsequent transfer of land in Shandong that was formerly ceded to Germany and to Japan without Chinese intervention or return to Chinese sovereignty. The May Fourth uprising also validated that a socialist revolution was possible in China (Miesner, 1999). 
sought to maintain autonomy and ideological separation from biomedicine. Classic medical texts were burned. Chinese medicine schools were closed, and classic Chinese medicine practitioners became the object of ridicule or physical attack, with their practices and pharmacies destroyed (Scheid, 2002). The governmental reduction of control and power granted to biomedical physicians and Chinese medicine practitioners, rendering them politically impotent, offers a sharp contrast to the integration achieved in a bottom-up manner from the political agency of, for example, Āyurvedic practitioners in India at approximately the same historical moment (Leslie, 1992); a democratic model of integration that was completely overlooked by the WHO.

Finally, Mao's attempt at integration cannot accurately be considered complete healthcare integration. First, Fang. (2012) identified that the Barefoot Doctors program was ultimately most successful in educating rural populations to utilize western pharmaceuticals, rather than any integrated combination of therapies. Second, the extent to which non-biomedical practices are integrated in the minds of the public may reveal more about the actual extent of integration. In modern China, TCM has been employed primarily according to perceived best interventions for particular ailments or as an adjunctive therapy with biomedicine (Scheid, 2002). But, the most important fact, that is often overlooked, is that not only were many local practitioners not integrated into the state medical system, but several types of practitioners were actually prohibited from practising. For example, though herbalists may have been eligible to become barefoot doctors, shamans and diviners were not $\left(\mathrm{Ha}{ }^{\circ} \mathrm{klev}, 2005: 6\right)$. Immediately, such conditionalities -concerning who may or may not be integrated into the healthcare system- problematizes the representation of Mao's model of integration as a true or complete integration of a country's plural practices and practitioners into the healthcare system. And yet, despite these myriad challenges to China's representation of healthcare integration, and despite the fact that as the WHO was adopting the China model, rural healthcare was being completely disassembled with the demise of the brigade unit after Mao's death; the WHO chose to perpetuate and globalize this model.

\section{Was the Primary Healthcare Model Attributed to the People's Republic of China, actually an American model in Republican China}

Thus far, we have made a fundamental assumption that this model, on which primary healthcare was based, began and ended with Mao. However, such assumptions can be challenged when considering the influence of the west, particularly the U.S., on Chinese healthcare in the Republican Period. The Rockefeller Foundation's John Grant sought 'an organized core of a regionalized system of community healthcare' and envisioned 'health for all' through his China rural program that predated Alma Ata by more than half a century (Grant, 1919; Yip, 1982: 1,200). As part of this program 'Village Health Workers and paramedics received short-term training in first aid and hygiene. These health workers were crucial in providing health information and simple curative and preventive services to their fellow villagers' (Yip, 1982: 1,203). This creation of a network of community health systems, with the expectation for community biomedical healthcare, 'formed an important part of the medical legacy that the Communists inherited' (ibid.).

In 1931, plans were made for rural health stations that would provide healthcare at the most local population level possible, using minimally trained village health aides (Yip, 1982). By 1934, with the help of John Grant, a functioning health district that consisted of a district health centre encompassing administrative offices, a fifty-bed hospital, a laboratory, and classrooms for training, plus seven subdistrict health stations that served more than seventy-five villages were developed (ibid.). Initiated in 1935, The Rockefeller Foundation's China Rural Health Program ended abruptly in 1937, due to the Japanese invasion of China (ibid.). Yet, it is questionable if this, Rockefeller Foundation program served as the actual model, or at the very least, a precursor to the model adopted first by Mao and later by the WHO. The relevance that this model attributed to China, may, in actuality, have been influenced, and possibly conceived, by others, highlights the central value of representation, which is needed to leverage the face of soft power in the geopolitical arena.

\section{CONCLUSION}

The story of how the international and global social capital gained from the export, transfer, and adoption of myriad Chinese healthcare activities has supported China's entry onto the world stage in the late 20th century, raises more questions than answers. Overall, this paper argues that though many of these activities would not be considered to be examples of soft power in and of themselves, their impact can be considered to have played a clear role in enhancing China's soft power and international social capital. This paper has attempted to unpack and critically examine the myriad factors involved in this evolution of soft power, from cultural transfers and migration, to the global export and, in the case of artemisinin, adoption and global scientific acknowledgement of Chinese medical practices, to the adoption of a Maoist model for universal and primary healthcare by the World Health Organization and the assumptions embedded in the WHO's representation of this model. These assumptions resulted from international and domestic political economic forces that can be traced from the early work of the Rockefeller Foundation in China to the need for Mao Zedong to demonstrate the value of communism in China through coercive and enforced resolutions to redress rural healthcare inequalities. Clearly, though often overlooked, the soft power representation of healthcare as an irrefutable gift to the world, as was headlined in Dr. Youyou's Nobel Prize acceptance speech, has proven and continues to prove quite effective for China's rise on the world stage. 


\section{ETHICS STATEMENT}

The studies involving human participants were reviewed and approved by Xi'an Jiaotong Liverpool University. All participants provided written or oral informed consent to participate in this study.

\section{REFERENCES}

Adloff, F., and Mau, S. (2006). Giving Social Ties, Reciprocity in Modern Society. Arch. Eur. Sociol. 47 (1), 93-123. doi:10.1017/s000397560600004x

American Society of International Law (1972). Representation of China within the United Nations System. Int. Leg. Mater. 11 (3), 561-570.

Andrews, B. (2014). The Making of Modern Chinese Medicine, 1850-1950. Honolulu: University of Hawaii Press.

Andrews, B. (1996). The Making Of Modern Chinese Medicine, 1895-1937, PhD Thesis. University of Cambridge.

Armstrong, J. (1997). "The Chinese at the Cape in the DEIC Period, 1652-1795, “ in Slave Route Project Conference, Cape Town, October, 1997.

Brautigam, D. (2009). The Dragon's Gift: The Real story of China in Africa. Oxford and New York: Oxford University Press.

Brown, E. R. (1979). Rockefeller Medicine Men: Medicine and Capitalism in America. Berkeley: University of California Press.

Brown, T. M., Cueto, M., and Fee, E. (2006). The World Health Organization and the Transition from "International" to "Global" Public Health. Am. J. Public Health 961, 62-72. doi:10.2105/ajph.2004.050831

Douglas, M. (1966). Purity and Danger: An Analysis of Concepts of Pollution and Taboo. Abingdon: Routledge.

Fan, K. (2007). Dayi jingcheng-Tangdai guojia, xinyang yu yixue [Physicians' Earnest Sincerity -State, Belief and Medicine in the Tang Dynasty] 大醫精誠— 唐代國家 信仰與醫學 Taipei: Dongda tushu gongsi

Fang, X. (2012). Barefoot Doctors and Western Medicine in China. Rochester, NY: University of Rochester Press.

Farquhar, J. (1994). Knowing Practice: The Clinical Encounter of Chinese Medicine. Boulder: Westview Press.

Gergen, K. J., and Gergen, M. M. (1971). "International Assistance from a Psychological Perspective," in Year Book of World Affairs 1971. Editors G. Keeton and G. Schwartzenberger (London: Stevens \& Sons), 87-103.

Grant, J. (1919). "The Most Efficient Manner in Which the International Health Board May Accomplish its Fundamental Purpose in China," in Midwifery Education, Midwifery Training School, Beijing (Report), Folder 372, Box 45, Series 601, RG1 (Rockefeller Foundation Archives, Rockefeller Archive Center).

Guanne, W. (2021). Research on the Overseas Dissemination and Popularization of Chinese Medicine. Trans. Compa. Edu. 3 (1), 55-62. doi:10.23977/ trance.2021.030110

Ha ${ }^{\circ}$ klev, S. (2005). Chinese Barefoot Doctors, a Viable Model Today. Working Paper, IDSC. doi:10.1163/1568554053148799

Harley, J. B. (1994). "Cartography in the Traditional East and Southeast Asian Societies," in The History of Cartography 2 Book-2 Chicago: University of Chicago Press.

Hsu, E. (2018). "Traditional Chinese Medicine: Its Philosophy, History, and Practice," in The International Encyclopedia of Anthropology. Editor H. Callan (Hoboken, NJ: Wiley), 1-10. doi:10.1002/9781118924396.wbiea2369

Huang, Y. (2010). Pursuing Health as Foreign Policy: The Case of China. Indiana J. Glob. Leg. Stud. 17 (1), 105-146. doi:10.2979/gls.2010.17.1.105

Kadetz, P. (2012). The Representation And Practice Of Healthcare Integration: Alterity and the Construction of Healthcare Integration in the Philippines. $\mathrm{PhD}$ thesis (University of Oxford).

Kadetz, P. (2013). Unpacking Sino-African Health Diplomacy: Problematising a Hegemonic Construction. St. Antony's International Review 82, 149-172.

Kadetz, P. (2014). Colonising Safety: Creating Risk through the Enforcement of Biomedical Constructions of Safety. East Asian Sci. Technol. Soc. 1, 81-106.

Kadetz, P., and Perdomo, J. (2011). Slaves, Revolutions, Embargoes, and Needles: The Political Economy of Chinese Medicine in Cuba. Asian Med. Tradition Modernity 61, 95-122. doi:10.1057/biosoc.2010.43

\section{AUTHOR CONTRIBUTIONS}

The authors confirm being the sole contributors of this work and have approved it for publication. PK conducted the research and drafted the original manuscript. MSB contributed to the editing and revision of the paper, including additions of historical data.

Lampton, D. (1974). Health, Conflict and the Chinese Political System. Ann Arbor: Center for Chinese Studies, the University of Michigan.

Lampton, D. (1977). The Politics of Medicine in China. Boulder: Westview Press. Lee, K. (2009). The World Health Organisation (WHO). London: Routledge.

Lei, S. H. (2014). Neither Donkey Nor Horse: Medicine in the Struggle over China's Modernity. Chicago: University of Chicago Press.

Leslie, C. (1992). "Interpretations of Illness: Syncretism in Modern Āyurveda," in Paths to Asian Medical Knowledge. Editors C. Leslie and A. Young (Berkeley: University of California Press), 177-208. doi:10.1525/california/ 9780520073173.003.0009

Li, Y. (2014). Acupuncture Journey to America: A Turning point in 1971. J. Traditional Chin. Med. Sci. 1 (2), 81-83. doi:10.1016/j.jtcms.2015.03.001

Lin, A. X., Chan, G., Hu, Y., Ouyang, D., Ung, C. O. L., Shi, L., et al. (2018). Internationalization of Traditional Chinese Medicine: Current International Market, Internationalization Challenges and Prospective Suggestions. Chin. Med. 13 (1), 9-6. doi:10.1186/s13020-018-0167-z

Litsios, S. (2004). The Christian Medical Commission and the Development of the World Health Organization's Primary Health Care Approach. Am. J. Public Health 9411, 1884-1893. doi:10.2105/ajph.94.11.1884

Liu, P., Guo, Y., Qian, X., Tang, S., Li, Z., and Chen, L. (2014). China's Distinctive Engagement In Global Health. The Lancet 384 (9945), 793-804. doi:10.1016/ S0140-6736(14)60725-X

Lucas, A. (1982). Chinese Medical Modernization: Comparative Policy Continuities 1930s 1980s. NY: Praeger.

Ma, Q. (1995). The Rockefeller Foundation and Modern Medical Education in China, 1915-1951. PhD thesis (Case Western Reserve University).

Magnussen, L., Ehiri, J., and Jolly, P. (2004). Comprehensive versus Selective Primary Health Care: Lessons for Global Health Policy. Health Aff. 233, 167-176. doi:10.1377/hlthaff.23.3.167

Mauss, M. (1990). The Gift: The Form And Reason For Exchange In Archaic Societies London: Routledge

Meisner, M. (1999). Mao's China and after: A History of the People's Republic. New York: Simon \& Schuster.

Mohan, G., and Tan-Mullins, M. (2009). Chinese Migrants In Africa As New Agents Of Development? An Analytical Framework. Euro. J. Develop. Res. 21.4, 588-605. doi:10.1057/ejdr.2009.22

Nobelprize.org (2021). The Nobel Prize. Tu Youyou Facts. Available at: https:// www.nobelprize.org/prizes/medicine/2015/tu/facts/(Accessed April 12, 2021.

Nye, J. (1990). Soft Power. Foreign policy 80, 153-171.

Nye, J. (2004). Soft Power: The Means to success in World Politics. NY: Public affairs.

Nye, J. (2017). Soft Power: the Origins and Political Progress of a Concept. Palgrave Commun. 3, 17008. doi:10.1057/palcomms.2017.8

Rockefeller Foundation (1917). International Health Board Report of 1917. NY: Rockefeller Archive Center.

Rosenthal, M. M. (1981). Political Process and the Integration of Traditional and Western Medicine in the People's Republic of China. Soc. Sci. Med. A: Med. Psychol. Med. Sociol. 15, 599-613. doi:10.1016/0271-7123(81)90083-3

Rotberg, R. I. (editor) (2009). China Into Africa: Trade, Aid, And Influence. Brookings Institution Press.

Scheid, V. (2002). Chinese Medicine in Contemporary China: Plurality and Synthesis. Durham: Duke University Press.

Scheid, V. (2001). "Shaping Chinese Medicine: Two Cases from Contemporary China," in Innovation in Chinese Medicine. Editor E. Hsu (Cambridge: Cambridge University Press), 370-404.

Siddiqi, J. (1995). World Health and World Politics: The World Health Organisation and the UN System. London: Hurst \& Co.

Sidel, V. W. (1973). Serve the People: Observations on Medicine in the People's Republic of China. New York: Josiah Macy, Jr. Foundation. 
Sun, J., and Lancaster, S. (2013). Chinese Globalization: A Profile of People-Based Global Connections in China. London: Routledge.

Tan, C. B. (editor) (2013). Routledge Handbook Of The Chinese Diaspora. New York: Routledge.

Tang, K., Li, Z., Li, W., and Chen, L. (2017). China's Silk Road And Global Health. The Lancet 390 (10112), 2595-2601. doi:10.1016/S0140-6736(17) 32898-2

Taylor, K. (2001). "A New Scientific and Unified Medicine: Civil War in China and the New Acumoxa, 1945-49," in Innovation in Chinese Medicine. Editor E. Hsu (Cambridge: Cambridge University Press), 343-369.

Taylor, K. (2005). Chinese Medicine In Early Communist China, 1945-1963: A Medicine Of Revolution. London: Routledge.

Unschuld, P. (1985). Medicine in China: A History of Ideas. Berkeley: University of California Press.

Walsh, J. A., and Warren, K. S. (1979). Selective Primary Health Care. N. Engl. J. Med. 301, 967-974. doi:10.1056/nejm197911013011804

Wang, V. W. (1996). All Dressed up but Not Invited to the Party: Can Taiwan Join the United Nations Now the Cold War Is over, 48. Ithaca, NY: Politics Faculty Publications and Presentations. Available at: https://digitalcommons.ithaca. edu/politics_faculty_pubs/48 (Accessed February 12, 2021).

World Health Organisation (2008). 'China's Village Doctors Take Great Strides. Bull. World Health Organisation 86.12, 909-988. Available at: http://www.who. int/bulletin/volumes/86/12/08-021208/en/(Accessed October 09, 2021).

World Health Organization (2018). Artemisinin Resistance and ArtemisininBased Combination Therapy Efficacy. Status report Available at: https:// apps.who.int/iris/bitstream/handle/10665/274362/WHO-CDS-GMP-2018.18eng.pdf (accessed 124, 2021).
Wu, L. T. (1959). Plague Fighter. The Autobiography of a Modern Chinese Physician. Cambridge: Heffer and Sons.

Yap, M., and Man, D. L. (1996). Colour, Confusion And Concessions: The History Of The Chinese In South Africa Hong Kong: Hong Kong University Press

Yip, K.-c. (1982). Health and Society in China: Public Health Education for the Community, 1912-1937. Soc. Sci. Med. 16, 1197-1205. doi:10.1016/02779536(82)90144-7

Youde, J. (2010). China's Health Diplomacy in Africa. China: Int. J. 8 (1), 151-163. doi:10.1142/s0219747210000099

Conflict of Interest: The author declares that the research was conducted in the absence of any commercial or financial relationships that could be construed as a potential conflict of interest.

Publisher's Note: All claims expressed in this article are solely those of the authors and do not necessarily represent those of their affiliated organizations, or those of the publisher, the editors and the reviewers. Any product that may be evaluated in this article, or claim that may be made by its manufacturer, is not guaranteed or endorsed by the publisher.

Copyright (c) 2022 Kadetz and Stanley-Baker. This is an open-access article distributed under the terms of the Creative Commons Attribution License (CC $B Y$ ). The use, distribution or reproduction in other forums is permitted, provided the original author(s) and the copyright owner(s) are credited and that the original publication in this journal is cited, in accordance with accepted academic practice. No use, distribution or reproduction is permitted which does not comply with these terms. 